\title{
Uso do WhatsApp em Atividades Educativas Extraclasse On-line no Ensino de Programação
}

\author{
Ernane Rosa Martins ${ }^{1}$, Luís Manuel Borges Gouveia ${ }^{2}$ \\ ${ }^{1}$ Instituto Federal de Goiás (IFG) \\ Caixa Postal 72.811-580 - Luziânia - GO - Brasil \\ ${ }^{2}$ Universidade Fernando Pessoa (UFP) \\ Caixa Postal 4249-004 - Porto - Portugal \\ ernane.martinseifg.edu.br, lmbg@ufp.edu.pt
}

\begin{abstract}
This article presents a teaching experience that involves the use of the WhatsApp application to perform extra class online, in the course of Web Programming of the course of Information Systems (IS). For that, a WhatsApp group was created in which the students could share the contents and at the end they answered an electronic questionnaire, obtaining 32 answers. The objective was to analyze the possibilities and potentialities of the use of extra class activities with the assistance of WhatsApp in Programming Teaching. It was found that online educational activities facilitated the promotion of teaching and learning of knowledge.
\end{abstract}

Resumo. Este artigo apresenta uma experiência de ensino que envolve a utilização do aplicativo WhatsApp para a realização de atividades extraclasses on-line, na disciplina de Programação Web do curso de Sistemas de Informação (SI). Para tal, foi criado um grupo do WhatsApp no qual os alunos puderam compartilhar os conteúdos e ao final responderam a um questionário eletrônico, obtendo-se 32 respostas. O objetivo foi analisar as possibilidades e potencialidades da utilização de atividades extraclasses com o auxílio do WhatsApp no Ensino de Programação. Verificou-se que as atividades educativas on-line facilitaram a promoção do ensino $e$ da aprendizagem dos conhecimentos.

\section{Introdução}

As tecnologias digitais e a Internet permitem atualmente aos alunos gerenciar seu aprendizado de forma autônoma, construindo sua aprendizagem através de processos informais e não formais, sem limitações de local e tempo, por meio de dispositivos móveis, aplicativos e redes sociais, extravasando os muros das escolas. Neste contexto caberá as escolas proporcionar aos aprendizes digitais, auxilia-los a selecionar em meio a imensidão de informações as mais pertinentes, estabelecendo o debate crítico e eficiente destas. Couto $(2013$, p. 2) afirma que "O professor não é mais aquele que transmite um determinado saber pronto. Ser professor na cultura digital implica 
coordenar, orientar, incentivar a aprendizagem colaborativa e cada vez mais personalizada".

As atividades de aprendizagem com dispositivos móveis ficam acessíveis aos alunos vinte e quatro horas por dia, sete dias por semana, permitindo acessos constantes ao aprendizado. Os alunos são beneficiados pela flexibilidade do horário e do local para estudo, além da comodidade de estudar em um dispositivo que os alunos já possuem e aplicativos que já conhecem. Looi et al. (2010) afirmam que os dispositivos pessoais encorajam a integração da educação na escola e fora dela, principalmente por causa da aprendizagem continuada, fornecendo novos espaços de aprendizagem.

Barbero (2014), afirma que no contexto atual a sociedade testemunha a aprendizagem contínua, onde a aprendizagem extravasa os espaços escolares, o tempo de aprender e o livro como única fonte de conhecimento, devido ao acesso aos dispositivos móveis, passou-se a ter aprendizagem em qualquer lugar, a qualquer tempo e com várias fontes de conhecimentos. Santaella (2013, p. 292) aborda a aprendizagem ubíqua, que foi possibilitada pelas tecnologias digitais e de conexão contínua, e que afetam diretamente as formas de ensinar e aprender, pela sua interatividade instantânea.

Conforme Moreira \& Simões (2017), diante de um novo modelo de ensino, que prima por práticas pedagógicas que visam mais do que a simples transmissão de conteúdo, é necessário repensar as práticas pedagógicas, sendo indispensável diversificar as maneiras de dar aula, apoiando-as com ferramentas que sejam capazes de gerar competências e habilidades nos estudantes, perante os desafios do presente.

As redes sociais, não são mais simples ambientes de interação social voltados ao lazer e diversão, mas se tornaram ambientes colaborativos, que permitem a construção de conhecimentos na área educacional. $\mathrm{O}$ uso destes ambientes, permitem ao professor, estender a interação para fora da sala de aula, estreitar a relação com seus alunos, identificar seus pontos fortes, assim como, suas dificuldades, gerando outras formas de avaliação e inclusão. Assim, a aprendizagem acontece de forma simples, espontânea e prazerosa, sendo todos os participantes agentes do conhecimento (Ferreira \& Magalhães, 2018).

O uso e a promoção do WhatsApp como extensão da sala de aula, pode proporcionar um ambiente de aprendizagem e de colaboração eficiente. Podendo tornar as aulas mais atrativas e prazerosas, aumentando as possibilidades de rendimento e de aprendizado, rompendo a fronteira espacial e temporal da sala de aula (Lopes \& Vaz, 2016). Sendo assim, este trabalho propôs investigar as possibilidades e potencialidades da utilização do aplicativo WhatsApp para a realização de atividades extraclasses on-line no Ensino de Programação.

Este artigo está estruturado em cinco seções. Nesta presente seção apresenta, além da introdução, a definição da problemática de pesquisa, o objetivo, a justificativa e importância do estudo e a estrutura da presente pesquisa. A seção 2 traz o referencial teórico, com a formação de uma base conceitual e teórica, que fornecem subsídios para o desenvolvimento deste estudo. Na seção 3 são apresentados o método empregado e as técnicas e procedimentos metodológicos utilizados. Na seção 4 estão descritos os resultados obtidos na pesquisa e discussão. Por fim, a seção 5 retoma o objetivo do artigo, como ele foi alcançado e propõe sugestões de pesquisas futuras. 


\section{Revisão Teórica}

Nesta seção é contextualizado a educação formal, não-formal e informal, assim como, o uso do WhatsApp na aprendizagem.

\subsection{Educação formal, não-formal e informal}

Não existe consenso na definição dos conceitos de educação formal, não-formal e informal, Vieira et al. (2005), definem educação formal como a que ocorre nos espaços formais de educação, a educação não formal ocorre em ambientes não formais, mas em situações onde existe a intenção de ensinar e desenvolver aprendizagens e pôr fím a informal é definida como a que ocorre em situações informais como conversa entre amigos. Segundo os mesmos autores, as situações informais são aquelas do cotidiano das pessoas como por exemplo os ambientes familiares, profissionais, de lazer e entretenimento, entre outros. Há autores que consideram a educação formal como sinônimo da educação escolar. Como Garcia (2005), este afirma que a educação escolar é onde o saber é sistematizado, justificando a definição de educação formal. Para o Ministério da Educação (MEC), a educação formal é aquela que ocorre nos sistemas de ensino tradicionais; a não formal corresponde às iniciativas organizadas de aprendizagem que acontecem fora dos sistemas de ensino; enquanto a informal e a incidental são aquelas que ocorrem ao longo da vida.

Segundo Xavier \& Fernandes (2008, p. 226), a sala de aula é considerada um ambiente convencional de ensino e os espaços fora da sala de aula são classificados como espaços não-convencionais de ensino. A sala de aula, como declaram esses autores, é um espaço físico preparado para a relação pedagógica, mas não é o único espaço para ação educativa. Para esses autores: "no espaço não-convencional da aula, a relação de ensino e aprendizagem não precisa necessariamente ser entre professor e aluno(s), mas entre sujeitos que interagem. Assim, a interatividade pode ser também entre sujeito e objetos concretos ou abstratos, com os quais ele lida em seu cotidiano, resultando dessa relação o conhecimento".

O uso de estratégias pedagógicas em espaços não-formais com o auxílio da tecnologia, podem promover a aquisição de novos conhecimentos. Propondo que o aluno tenha uma postura mais investigativa e com maior autonomia em seus estudos. $\mathrm{O}$ papel do professor neste contexto é de instigar os alunos a buscar e refletir sobre novas questões, para poder incrementar as discussões em sala de aula. O professor deve sempre que julgar importante, realizar intervenções de modo a focar os alunos nos fatores específicos e necessários para alcançar os objetivos estabelecidos. Sendo essencial o planejamento preliminar, para otimizar a qualidade das atividades e alcançar seus objetivos.

\subsection{WhatsApp na aprendizagem}

A maioria dos estudantes tem aparelho celular, por isto estes merecem atenção no âmbito educacional, pela possibilidade de serem aliados do processo de ensino, permitindo a aprendizagem a qualquer hora e em qualquer lugar. A união entre dispositivos móveis e educação, é denominada de Mobile Learning, onde os dispositivos móveis são utilizados dentro e fora de sala de aula para auxiliar o processo de aprendizagem. Esta prática pode ser concretizada por meio do uso do aplicativo 
WhatsApp Messenger, que é um aplicativo multiplataforma, gratuito, que permite a troca de mensagens pelo celular, criar grupos, enviar mensagens ilimitadas com imagens, vídeos e áudio, compartilhar sua localização e fazer backup do conteúdo postado nos grupos, etc (Oliveira et al., 2014).

O aplicativo WhatsApp pode ser uma ferramenta importante de debates, aulas interativas e de produção intelectual dos estudantes, por proporcionar, comunicação virtual, troca de mensagens e aquisição continua do conhecimento. Além de possibilitar a ação comunicativa entre professor-aluno e aluno-aluno, o compartilhamento de informações, a formulação de ideias e a resolução de problemas. $\mathrm{O}$ aplicativo permite a quebra das barreiras físicas da escola e possibilita novas formas de ensinar e aprender (Moreira \& Simões, 2017).

Assim, o WhatsApp aparentemente apresenta potencial para ser utilizado como apoio ao ensino e à aprendizagem por possibilitar a realização de buscas, compartilhamentos e comunicação, podendo gerar a construção de conhecimento em diferentes áreas. Com o uso do WhatsApp, estudantes e professores têm acesso a uma plataforma de comunicação que permite o compartilhamento de materiais didáticos em diferentes formatos, tais como: texto, áudio, vídeo e imagens. Podendo ser consultados, estudados e compartilhados a qualquer momento e em qualquer lugar (Schiehl; Martins \& Santos, 2017).

Existem diversos trabalhos sobre a utilização do WhatsApp no ensino, tais como: Rambe \& Bere (2013) investigaram o papel do WhatsApp no acesso à informação e na construção de conhecimentos para recursos educacionais gerados de maneira coletiva. Oliveira et al. (2014) relatam a aplicação do WhatsApp como facilitador de comunicação entre estudantes e o tutor de sala. Martins \& Gouveia (2018) buscaram compreender as possibilidades e potencialidades da utilização do WhatsApp no Ensino Médio, por meio das percepções dos participantes em relação a: perfil, uso da Internet e WhatsApp, aprendizagem, socialização, informação e desempenho. Paulino et al. (2018) busca compartilhar uma experiência bem-sucedida do uso do aplicativo WhatsApp como recurso para a educação médica, destacando o potencial pedagógico e formativo das redes sociais, ainda não aproveitado plenamente pelas universidades. Diferente destes, este estudo busca explorar as possibilidades e potencialidades da utilização do aplicativo WhatsApp para a realização de atividades extraclasses on-line focando no Ensino de Programação.

\section{Metodologia}

A pesquisa baseia-se em um estudo de caso de natureza qualitativa e quantitativa, de abordagem exploratória e descritiva, com pesquisa documental e questionários. Segundo Yin (2003), os estudos de caso descrevem um fenômeno ou intervenção no contexto em que ocorre. A revisão bibliográfica permitiu levantar informações sobre o assunto, estabelecendo a direção a ser percorrida e a formulação da questão de pesquisa. Os alunos acessaram os conteúdos em um grupo do WhatsApp, o qual foi utilizado como ferramenta de aprendizado e posteriormente com a aplicação de um questionário eletrônico junto aos discentes, obteve-se 32 respostas dos alunos da disciplina de Programação Web do Curso de Bacharelado em Sistemas de Informação. O formulário 
utilizado foi criado no Google Docs. Utilizou-se ainda as notas do diário do professor, observação e entrevistas face a face feitas ao término da proposta interventiva.

O grupo criado foi utilizado como: fóruns de discussão, central para tirar dúvidas, no desenvolvimento de textos colaborativos e no compartilhamento de links, vídeos, sites, imagens e áudios, permitindo a realização de atividades extraclasses online. A Análise de Conteúdo (AC) foi aplicada aos dados coletados a partir das perguntas. A AC compreendeu as seguintes etapas: organização dos dados, codificação, categorização, inferências e interpretação. Conforme Bardin (2010), a AC tem como princípios a "exaustividade", "representatividade" e "pertinência". Assim, os dados foram tabuladas com o software Excel e analisados de acordo com o referencial teórico.

\section{Resultados}

Nesta seção discorreremos acerca do experimento realizado, sendo que no primeiro contato com os alunos foram expostos os objetivos da pesquisa e a sua pretensão de investigar e constatar se de fato o WhatsApp poderia ser utilizados pedagogicamente como extensão da sala de aula no Ensino de Programação. Em seguida, em um segundo encontro com os alunos ficou estabelecido um conjunto de normas e critérios de uso e participação no grupo, sendo que na ocasião todos se comprometeram a seguir as determinações criadas conjuntamente, pois as tais regras não teriam caráter de imposição, uma vez que os próprios alunos participaram na sua construção. Após a criação e aprovação das regras de participação dos grupos, foram colhidos os números telefônicos dos alunos e do professor, sendo finalmente criado o grupo da disciplina. Entre as funções estabelecidas para o grupo, ficaram definidas:

- Trabalhar os conteúdos abordados em sala de aula;

- Possibilitar a troca de informações, discussões, compartilhamento e produção de textos, vídeos, fotos, links, áudios e demais materiais que possam servir de apoio ao estudo e a construção de conhecimento dos conteúdos trabalhados em sala de aula;

- Espaço para que o professor e os alunos pudessem esclarecer dúvidas;

- Possibilitar aos alunos que possuem maior entendimento dos conteúdos, colaborar na aprendizagem dos demais membros do grupo;

- Espaço para a resolução de atividades, trabalhos e exercícios propostos pelo professor.

O grupo ficou ativo durante todo o semestre, com horário definido para o envio das dúvidas (até as 18:00 horas) e prazo estipulado para o feedback das respostas (até as 18:00 do dia seguinte). Ao final foram discutidos os resultados obtidos, a participação dos alunos e do professor. Verificando-se os limites e as possibilidades do uso da ferramenta como extensão da sala de aula.

A partir da análise das respostas dos alunos foram organizadas três categorias específicas, sendo: a) à estratégia utilizada; b) à eficiência da estratégia e c) à construção do conhecimento adquirido. Em cada uma das categorias separou-se alguns recortes das respostas mais significativas que representavam as opiniões dos discentes. 


\subsection{Quanto à estratégia}

Nesta categoria observa-se que os sujeitos associaram a estratégia como uma intervenção dinâmica e participativa.

- "Contribui de forma dinâmica ao aprendizado";

- "Muito interessante pois deixa a aula mais dinâmica";

- "Contribuiu na integração entre os colegas de classe";

- "Acesso fácil, facilidade, comunicação, debate e rapidez";

- “Aumentou a participação dos alunos".

\subsection{Eficiência da estratégia}

Pode-se identificar que os discentes associaram a estratégia como uma forma adequada, consistente e significativa para a aprendizagem.

- "Possibilitou adiantar conteúdos e assuntos";

- "Permitiu revisar os assuntos mais facilmente";

- "Permitiu o uso de vídeos, áudios e imagens para melhor ilustrar o conteúdo";

- "Permitiu a socialização";

- "Permitiu estudar em qualquer lugar e ter o professor sempre por perto";

- "Proporcionou aprendizagem coletiva, colaborativa e trocas de conhecimento";

- "Ajudou a tirar dúvidas sem ter que esperar até a próxima aula";

- "Aumentou a comunicação com o professor".

\subsection{Construção do conhecimento adquirido}

Os sujeitos participantes identificaram a estratégia como uma forma de se construir o aprendizado coletivamente.

- "Possibilitou a procura por conhecimentos mais avançados";

- "Aumentou a interatividade e o compartilhamento de conhecimento";

- "Aumentou a motivação e a colaboração";

- "Estimulou o raciocínio coletivo";

- "Promoveu o debate e a troca de conhecimentos pelo grupo";

- "Sentimos o professor mais presente e atuante dentro e fora da sala de aula";

- "Melhorou a relação do professor com os alunos";

- "Facilitou os estudos";

- "Deixou as aulas menos chatas";

- "Proporcionou mais tempo para estudar";

- "Ajudou a tirar as dúvidas"; 
- "Proporcionou aos alunos estudar mais e ajudar os colegas";

- "Facilitou entender temas que não entendiam, com as explicações do professor".

\subsection{Discussão}

Com a adoção da ferramenta WhatsApp, pôde-se perceber a manutenção da qualidade do processo de aprendizagem, mensurada através dos resultados alcançados por meio do aumento das notas da turma. No ano anterior, a média da disciplina foi de 5,33. Mas com a utilizado desta nova proposta pedagógica, a média foi para 8,41. Observou-se também melhora no comportamento dos estudantes e na procura por conhecimentos mais avançados em relação ao conteúdo da disciplina.

Os debates e questionamentos gerados, foram sintetizados, estruturados, agrupados e expostos na Tabela 1 .

Tabela 1. Principais resultados encontrados.

\begin{tabular}{|c|c|c|c|}
\hline & Pontos positivos & Pontos negativos & Sugestões \\
\hline Alunos & $\begin{array}{l}\text { - Facilitou o estudo de } \\
\text { forma geral; } \\
\text { - Possibilitou aos alunos } \\
\text { ajudarem uns aos outros; } \\
\text { - Facilitou o estudo de } \\
\text { assuntos com mais } \\
\text { dificuldade de aprender } \\
\text { somente com a ajuda do } \\
\text { professor; } \\
\text { - Ajudou a tirar as dúvidas } \\
\text { fora da sala de aula; } \\
\text { - Melhorou a comunicação } \\
\text { entre os alunos e o } \\
\text { professor; } \\
\text { - Permitiu estudar em } \\
\text { qualquer lugar com a ajuda } \\
\text { mais presente do professor. }\end{array}$ & $\begin{array}{l}\text { - Muita } \\
\text { desnecessária, conversa } \\
\text { estabelecendo as regras; } \\
\text { - Solicitações de respostas } \\
\text { imediatas, mesmo com o } \\
\text { prazo estabelecido; } \\
\text { - Muitas perguntas repetidas, } \\
\text { por não conseguirem } \\
\text { acompanhar as postagens; } \\
\text { - Internet lenta para ver os } \\
\text { vídeos. }\end{array}$ & $\begin{array}{l}\text { - Melhorar } \\
\text { o wi-fi da } \\
\text { instituição; } \\
\text { - Utilizar } \\
\text { em outras } \\
\text { disciplinas. }\end{array}$ \\
\hline Professor & $\begin{array}{l}\text { - Aumento significativo das } \\
\text { notas; } \\
\text { - Aumento da participação } \\
\text { dos alunos nas aulas } \\
\text { presenciais, principalmente } \\
\text { os que antes eram menos } \\
\text { participativos; } \\
\text { - Possibilitou adiantar } \\
\text { alguns conteúdos; } \\
\text { - Possibilitou conhecer } \\
\text { melhor os alunos; } \\
\text { - Possibilitou uma } \\
\text { aprendizagem coletiva e } \\
\text { colaborativa; }\end{array}$ & $\begin{array}{l}\text { - Postagem de dúvidas em } \\
\text { qualquer horário, mesmo } \\
\text { sendo estabelecido uma regra; } \\
\text { - Sobrecarga de postagens } \\
\text { com dúvidas, direcionadas } \\
\text { para o professor responder. }\end{array}$ & $\begin{array}{l}\text { Solicitar } \\
\text { que os } \\
\text { melhores } \\
\text { alunos } \\
\text { auxiliem o } \\
\text { professor } \\
\text { nas } \\
\text { respostas } \\
\text { das dúvidas } \\
\text { dos alunos. }\end{array}$ \\
\hline
\end{tabular}




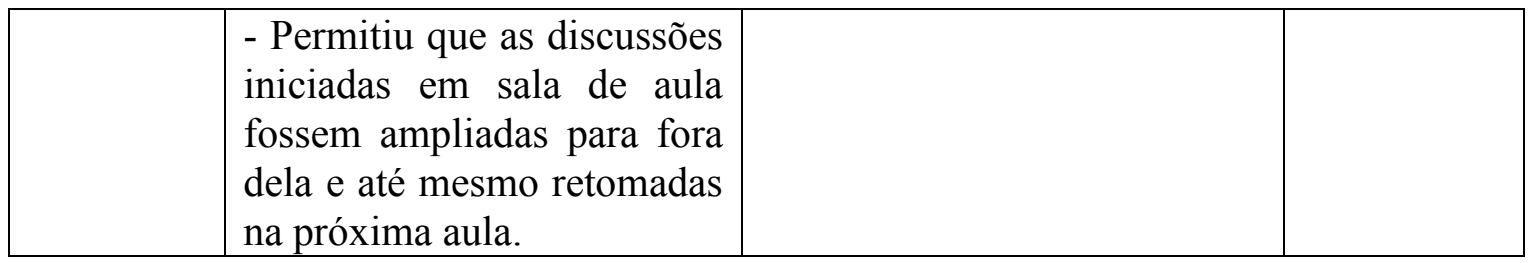

Um ponto a ser destacado foi a enorme quantidade de materiais de estudos em diversos formatos que foram disponibilizados no grupo. Um dos principais recursos utilizados pelos alunos e professor, foram os áudios com explicações ou contribuições sobre o conteúdo. Também foram postados muitos links possibilitando encontrar facilmente os material sobre os temas abordados. Outro fato importante foi a ocorrência de questionamentos repetidos, alguns alunos não acompanhavam o histórico do grupo e acabavam perguntando a mesma coisa que outros colegas já haviam perguntado.

Este estudo confirmou outros já realizados, que também apontaram o potencial pedagógico do WhatsApp, tais como: Rambe \& Bere (2013), interatividade, compartilhamento de conhecimento, motivação, colaboração, sincronicidade e assincronicidade; Park, Cho \& Lee (2014), sensação de presença, compartilhamento da emoção; e Padrón (2013), baixo investimento. Diferente dos demais, este estudo identificou outros benefícios pedagógicos, tais como: procura por conhecimentos mais avançados ou de difícil entendimento, estimulo do raciocínio coletivo, melhora na relação do professor com os alunos, mais facilidade e tempo para os estudos, maior facilidade para tirar as dúvidas com o professor e colegas, proporcionou aprendizagem coletiva e colaborativa, e possibilitou a ilustração dos conteúdos por meio de vídeos, áudios e imagens.

As conclusões das discussões direcionaram para a concordância de que o WhatsApp pode ser utilizado efetivamente como extensões da sala de aula, desde que sejam seguidas regras pré-estabelecidas de cunho pedagógico. Assim, baseado na experiência e na revisão da literatura, surgiram algumas sugestões de como melhorar a utilização do WhatsApp no Ensino de Programação, as principais foram: estabelecer a finalidade do uso da ferramenta; definir regras claras de utilização; estipular horário determinado para atendimento aos alunos e registro das interações.

\section{Considerações Finais}

Este trabalho propôs investigar as possibilidades e potencialidades da utilização do aplicativo WhatsApp para a realização de atividades extraclasses on-line no Ensino de Programação. Na sociedade atual os novos dispositivos tecnológicos tem papel principal no cotidiano dos indivíduos, sendo necessário repensar as práticas educacionais e as práticas dos professores visto as mudanças proporcionadas pelas mídias digitais, redefinindo papéis e novas formas de pensar. A aprendizagem fora da sala de aula mostra-se complexa, por envolver a vida diária dos alunos. Os professores precisam se preparar para criar e adaptar os conteúdos educacionais para utilização nos dispositivos móveis.

Ao final do semestre os alunos sentiram-se motivados e ativos dentro do processo de aprendizagem, pois possibilitou a escolha dos conteúdos mais pertinentes e 
quando acessar e disponibilizar os mesmos. Durante o desenvolvimento da atividade foram expostas diversas dificuldades práticas em relação aos assuntos, sendo estas esclarecidas pelo professor, consolidando e lapidando esses conceitos nos alunos de forma iterativa fora e dentro da sala de aula. Alguns alunos conseguiram vislumbrar, outras vertentes de pesquisas não triviais. Muitos alunos buscaram conteúdos que não foram disponibilizados pelo professor, demonstrando grande flexibilidade e crescimento na autonomia. Os alunos se sentiram à vontade para utilizar o aplicativo com fins pedagógicos, mesmo mediante a supervisão e orientação planejada do professor.

A atividade permitiu amadurecer o desenvolvimento dos alunos dentro do contexto da aprendizagem, interagindo com aspectos múltiplos dentro de um eixo de aprendizagem. Outra constatação relevante foi que a prática autodidata pode ser desenvolvida nos alunos através deste tipo de atividade, ampliando o caráter investigativo nos alunos, assim como, o interesse em procurar ajuda. A principal conclusão que se pode chegar é que, este tipo de atividade, solidifica fortemente o aprendizado e visa garantir um maior aproveitamento dos conceitos. A realização desta pesquisa, levou professores de outras disciplinas a adotarem a criação de grupos com finalidade pedagógica em diferentes turmas, e até mesmo a direção da escola passou a usar grupos para se aproximar dos alunos, expor avisos e se comunicar com os pais dos alunos na tentativa de trazê-los, mesmo que de forma virtual, para mais perto da instituição de ensino.

Os alunos apreciaram o compartilhamento de materiais, mensagens instantâneas, oportunidade de fazer upload de arquivos, as discussões e receber notificações instantâneas. Todos os alunos aprovaram a comunicação e discussão que a ferramenta proporcionou entre os alunos e com o professor, se mostrando favoráveis com a utilização do WhatsApp na educação. A grande maioria dos alunos, afirmaram que a participação no grupo do WhatsApp facilitou a promoção do ensino e da aprendizagem dos conhecimentos. A tecnologia móvel cada vez mais vem se mostrando como uma forte aliada para aqueles com dificuldades devido as grandes distâncias entre suas casas e as escolas. Visto que perante a disponibilidade de um celular com Internet, estes podem acessar os conteúdos específicos das aulas e interagir com o professor e os demais alunos, com enorme eficiência. Para continuidade desta pesquisa serão realizados novos estudos em projetos semelhantes em outras turmas e cursos para comparação e confirmação dos resultados.

\section{Referências}

Barbero, J. M. (2014). A comunicação na educação. Tradução: Maria Immacolata Vassallo de Lopes e Dafne Melo. São Paulo: Contexto.

Bardin, L. (2010). Análise de conteúdo. 4. ed. Lisboa: Edições70.

Couto, E. S. (2013). Educação 3.0 é a tecnologia que integra pessoas. Disponível em: http://porvir.org/porfazer/educacao-3-0-e-tecnologia-integra-pessoas/20130326. Acesso em: 12 de Agosto de 2018.

Ferreira, S. da S. and Magalhães, R. S. R. (2018). Ambientes Virtuais de Aprendizagem Colaborativos: O Uso do Facebook na Aprendizagem. Anais da Semana de Informática Educacional do IFPI - Campus Teresina Zona Sul, p. 34-37. 
Garcia, V. A. (2005). Um sobrevôo: o conceito de educação não-formal. In: PARK, M. B \& FERNANDES, R. S. Educação Não-Formal - Contextos, percursos e sujeitos. Campinas: Unicamp/CMU, Editora Setembro.

Looi, C-K., et al. (2010). Leveraging mobile technology for sustainable seamless learning: A research agenda. British Journal of Educational Technology. p. 154-169.

Lopes, C. G. and Vaz, B. B. (2016). O Uso Pedagógico dos Grupos do Whatsapp no Ensino de História. In: V Congresso Internacional de História - Novas Epistemes e Narrativas Conteporâneas, Jatai.

Martins, E. R. and Gouveia, L. M. B. (2018). O Uso do WhatsApp como Ferramenta de Apoio a Aprendizagem no Ensino Médio. RENOTE Revista Novas Tecnologias na Educação, v. 16, nº 2, p. 1-10.

Moreira, M. L. and Simões, A. S. de M. (2017). O uso do whatsapp como ferramenta pedagógica no ensino de química. ACTIO, Curitiba, v. 2, n. 3, p. 21-43.

Oliveira, E. et al. (2014). Estratégias de uso do Whatsapp como um ambiente virtual de aprendizagem em um curso de formação de professores e tutores. In: Simpósio Internacional de Esducação a Distância - SIED, Encontro de Pesquisadores em Educação a Distância - EnPED, São Carlos, p. 1-15.

Padrón, C. J. (2013). Estrategias Didácticas basadas en Aplicaciones de Mensajería Instantánea WhatsApp exclusivamente para Móviles:(Mobile Learning) y el uso de la Herramienta para promover el Aprendizaje Colaborativo. Eduweb, v. 7, n. 2, p. 123-134.

Park, S.; Cho, K. and Lee, B. G. (2014). What Makes Smartphone Users Satisfied with the Mobile Instant Messenger?: Social Presence, Flow, and Self-disclosure. International Journal of Multimedia \& Ubiquitous Engineering, v. 9, n. 11.

Paulino, D. B.; Martins, C. C. de A.; Raimondi, G. A. and Hattori, W. T. (2018). WhatsApp ${ }^{\circledR}$ como Recurso para a Educação em Saúde: Contextualizando Teoria e Prática em um Novo Cenário de Ensino-Aprendizagem. Revista Brasileira de Educação Médica, v. 42 (1): 166 - 178.

Rambe, P. and Bere, A. (2013). Sing mobile instant messaging to leverage learner participation and transform pedagogy at a South African University of Technology. British Journal of Educational Technology. 44, 4, p. 544-561.

Santaella, L. (2013). Comunicação ubíqua: repercussões na cultura e na educação. São Paulo: Paulus.

Schiehl, E. P.; Martins, L. P. R. and Santos, L. M. dos. (2017). WhatsApp como uma ferramenta de apoio na construção do conhecimento de sequências numéricas no primeiro ano do Ensino Médio. Revista Tecnologias na Educação - Ano 9 Número/Vol.19.

Vieira, V.; Bianconi, M. L. and Dias, M. (2005). Espaços Não-Formais de Ensino e o Currículo de Ciências. Ciência \& Cultura. v.57, n.4, Out/Dez. p.21-23.

Xavier, O. S. and Fernandes, R. C. A. (2008). A Aula em Espaços Não-Convencionais. In: VEIGA, I. P. A. Aula: Gênese, Dimensões, Princípios e Práticas. Campinas: Papirus Editora.

Yin, R.K. (2003). Case Study Research: Design and Methods (3rd Ed.). Thousand Oaks, CA: Sage. 